\title{
Analysis of the Present Status and Exploration of the Mode to Art Design Education in College
}

\author{
Xiaobo Sun ${ }^{1, a}$ \\ ${ }^{1}$ Art College, Northeast Dianli University, Jilin 132012, China. \\ axiaobo_sun@126.com
}

Keywords: art design education, teaching mode, analysis \& explore.

\begin{abstract}
With the development of the globalization of economic and cultural integration, the art design education advance has lagged behind the era. In this paper, the literature data, questionnaire survey and interviews with experts, logical reasoning, comparisons and charts and so on taking, all colleges and universities is used to domestic current Art Institute Expansion and cultural studies. the quality of students, the quality of teachers, teaching mode, such as social practice as a case is carried out by visiting teachers, students discussion on the same academic reform experience. The related art design company staff survey methods, combining education and management theory is proposed specific measures and make a of exploratory analysis art design of the new model in order to promote the development of college art design education.
\end{abstract}

\section{Introduction}

The term "design" has been widely used in recent years. People often interpret "design" as a method of design, pattern design, etc. in advance of a formal work, according to a certain purpose. Imagination and planning, that is, before the act of imagination, imagination, thought or pre-developed specific content and steps. A process of planning, planning, envisioning, problem solving, and visual communication. Practice has proved that the concept of design is based on the direct needs of daily life and production needs to build up, and human-specific, conscious, non-instinctive behavior. The so-called art and design, from the connotation that is from the technical, economic, social, material and cultural point of view, the functional utility and pleasant for the purpose of using a certain material materials and technology, the use of certain artistic means , According to the law of the United States to carry out the concept of planning, so that it has a specific function, external form, interpersonal relationships and cultural significance of the practical activities of creative products. Art and design of the extension is more extensive, involving clothing, food, shelter, and other human life in all areas and all levels. From the perspective of its function and esthetics, it not only includes the design of practical functional goods, but also the creation of ornamental products which are more aesthetically outstanding. From the developmental property of unity of art and technology, Including handicrafts as the medium of the traditional design, but also to industrial production based on the modern design.

The so-called art and design education, art design is an integral part of it not only to cultivate art and design talent, but also standardize the art and design career model. From a narrow sense, art and design education is through the basic theory of art and design, basic knowledge, through the ability of art design, design awareness training, through the art design methods, design skills training, training with innovative quality and sustainable development potential , Capable of artistic design, creation, teaching, production and management of specialized personnel training methods. From a macro point of view, art and design education is not limited to a division of the industry based on the transfer of skills and design experience of the inheritance and development of the main line, vocational skills education as the goal, but a built on Rational and harmonious development of personality education based on the modern industrial production and traditional arts and crafts production in the design of art content, scientific content, the realization of cultural connotations as the main line to the creation of people's quality and ability to cultivate the core Education. 
But the truth tells us that the design power $\neq$ design power. The current Chinese design education, characterized by "scale expansion", will not only promote the development of China 's innovative design, but may become the biggest obstacle to a high level of improvement. Many institutions immersed in the campus of the huge, modern hardware, "joy", forget the "training of innovative talents," the essence of design education. Therefore, the rapid expansion of art and design education at the same time, the decline in the quality of education led to the degradation of the entire educational system function, it becomes the inevitable result.

\section{The Problems of Art Education in China}

In recent years, the enrollment and enrollment of art majors continue to heat up, although it reflects the trend of the society's demand for art and the popularization of art, but its problems are worth pondering.

Many colleges and universities in China, driven by economic interests, the art design specialty as a school income-generating professional, not from their own geographical characteristics, cultural characteristics, school professional advantages to develop their own characteristics, resulting in professional settings on the duplication and waste.

The direct cause of the rapid expansion of the art profession is considerable tuition. It is understood that the national arts students in the annual tuition fees generally around 10,000 yuan, and even some institutions to receive tuition fees only 15,000 yuan, much higher than other professions. More than a year to recruit hundreds of people will bring millions of institutions to the proceeds. In 2007, although the education management department issued the "art college entrance examination warning", but in the northeast, southwest and other places of art colleges have appeared in the scale of more than 10,000 students in the collegiate.

With the "sparrow is small, fully equipped" to describe the current department of the University of China to set appropriate, however. In recent years, a comprehensive university to do art has become a trend, coupled with the income of the filling, so that the original art department and the Department does not have the faculty of the institutions, have flocked, have to do art classes . This system makes the weak on the quality of education and teaching and research level of teachers is more worrying.

The expansion of enrollment in universities may eventually lead to teaching conditions that can not meet the needs of teaching, and the quality of teaching is difficult to improve. There are a large number of problems, such as lax student enrollment, uneven student cultural foundation, special circumstances of students and difficulties in education and management.

Art and design education teachers arbitrarily great, because people set up classes, blindly increase or decrease. Because of short-term rapid expansion of the school, resulting in the teaching system is not a solid development in the development of art and design education, especially in the treatment of foreign art and design education experience and results, blindly, without careful discrimination, resulting in chaotic teaching model behind teachers Structural deviation and other issues.

Although China 's higher education of arts and crafts has gone through a hundred years of history, but strictly speaking, with a modern sense of industrial products as the main design education is only a quarter of a century. In order to meet the community's demand for art and design talents, the state has formulated a series of policies to expand the enrollment scale. profession. Art Academy, Academy of Fine Arts, School of Design, School of Animation and other two colleges have also been established in these universities, the development trend of the fierce, large-scale are unprecedented. However, China's art and design education from the art education derived from, and more from the arts and crafts professional name, is an art-based design pattern, has been less emphasis on technology, economic ties, do not take into account the economy The influence of design, follow this design pattern makes the development of modern art design in China has been a great restraint. From the education system and design community for the design of education for more than 20 years of development understanding of the point of view, China's design is clearly in the "market affects" model, rather than "thought affects", "social impact" model. Even today, the domestic design education, although the surface is very busy, in fact, in the education system and the early 20th 
century, 80 no essential difference. Many people think that an increase in the number of computer courses is the modernization of education, in fact, just learn a few software operations, social and economic progress has not been reflected in the art and design education.

\section{Disciplinary Status of Design Schools in China}

Throughout the current design disciplines in China's design institutes, is nothing more than graphic design, environmental art and design, industrial modeling, clothing, animation, ceramics, decoration, display and so on. With the development of economic life, the expansion of economic production, the interdisciplinary setting can not meet the needs of today's society, Can not be cultivated, on the other hand, the same professional and recent large-scale enrollment has led to the graduates into society after a lot of unnecessary competition and talent waste. From the current design teaching system in China, from the late 1970s the introduction of the Bauhaus design teaching system is still in use today, the three constitute the domination of the world, infiltration to various professions, this design teaching showed a significant lag state, Its specialty is the formation of geometric form of training, ignoring the specific shape design, training, rational, mechanical, cold, monotonous design style.

Since China's modern art design education started late, and are in the traditional arts and crafts education under the thinking mode of gradually established, so China has been the art and design education thinking and patterns are used in the original arts and crafts education ready-made format, pay attention to Step by step, standardized procedures, fixed teaching methods, obliterate the teaching and learning of personality development, making the design and the market is far apart, the theory and practice out of line.

Art and design is a very practical professional, whether it is environmental art design, or visual communication design, whether product design, or clothing design, each field requires graduates to face the actual business, in practice to solve problem. The design practice teaching in design colleges is the weakest link in design education. The teaching of most departments (specialty) is only on paper. There is no corresponding practice base. The design and production of students is basically a hypothetical topic. Demand out of line, can not enable students to understand the real needs of enterprises and get effective training. While allowing students to encourage the development of thinking in the school phase, allowing students to produce some cultural and imaginative thinking of the subject. But the purpose of student learning is mainly for the social training delivery of talent, and now students in the actual production of almost all aspects of the various links do not know, students feel unable to enter the role after graduation, many of the necessary work but not in school training And learning knowledge, so that the design of art education in colleges and universities reduced to a "pre-class" level, it is difficult for the contemporary social development of qualified personnel, so that design education in a semi-finished product results. This level of design education in the face of China's highly developed economic and social needs is very unsatisfactory.

\section{Research on the New Pattern of Art Design Education in China}

We look at the history of world design education will find that art and design has become the world's art and modern science and technology strong combination of ties. The development of art design education must follow the development of modern economy in order to promote the development of art design. As an institution of higher education in design art, it is always a center for the dissemination of new ideas of the times. Design of art education is benign, the most important thing is not to set up what kind of professional institutions, what courses and to teach students what kind of skills, but rather in design education, the advanced nature of ideas and practices, can guide the design The trend and the contemporary design practice in China has a guiding significance.

Art design in the training objectives and teaching content, etc. are different from the pure art, so the content of college entrance examination questions can not be pure art, not to mention pure art 
professional examination content for the sketch and the rationality of the color remains to be further studied, Should pay more attention to the overall quality of students and creative ability.

Art design as a comprehensive discipline, requires knowledge-based. However, the current situation of college art design professional enrollment situation, the degree of the requirements of the candidates for cultural courses is not enough, as long as the acceptance of cultural subjects in line, according to professional results sorted merit, which is not conducive to improving the cultural quality of students. Accordingly, art and design as an art professional enrollment time, may be appropriate to improve the culture of candidates in the proportion of admission scores. In recent years, some colleges and universities in the provinces and cities have all apply for the art of professional candidates of the matriculation test results are all included in the total score of their cultural examinations, in order to improve students' cultural accomplishment has taken a welcome step.

\section{Summary}

It is helpful for us to understand the development and problems of art design education in our country today, and to review and study the development of Chinese art design education, summarize and analyze its experiences and lessons. The development of art design education in China is a product of modern Chinese society. For more than a half century, it has gone through a long and tortuous road of development. It has gone through four stages: the late Qing Dynasty, the Republic of China, the early period of new China and the reform and opening- Stage, which is no lack of foreign art and design education on China's influence. Every step forward is full of hardships, each of the original model of reform and breakthrough, are immersed in a generation after generation of people interested in art and design education efforts and sweat. It is this arduous journey, fearless exploration of the process, China's art and design education from scratch, from small to large, although still in the initial stage of development, distance to build a mature and perfect education system, education model A long way to go. But a half century in the accumulation of rich experience and lessons for the education of art and design to lay the foundation for the road to maturity.

\section{References}

[1] Kou Zhong.Comparison of Art Design Education between China and America.Journal of Nanchang Teachers College of Vocational Technology, 2002 (2).

[2] Some Reflections on the Teaching Reform of Art Design in Colleges and Universities. Art Research, No.2,2002.

[3] Liao Jun. Reflections on Art Design Education in Australia, Journal of Soochow University, December 2002.

[4] Li Jun.Creating Art Design Education Platform and Constructing the Mode of Studio Teaching Group - Analysis of the Mode of Teaching Group under the Credit System in Art Colleges and Universities.Art Education, August, 2007.

[5] Zheng Shushen. After the inspection contrast - on the art and design education. Art observation, 2001 ninth issue.

[6] Zheng Han. Chinese Art Design in Transition. Journal of Shanghai Institute of Technology, Nov. 2002, pp. 80-82.

[7] A Study of the Development of Chinese Art Design Education. Beijing: Beijing Institute of Technology Press, July 2003. 287.

[8] Lvping.Research on the Current Situation and Development of Art Design Education in Universities in Guangxi.Master Dissertation of Guangxi Normal University, May 2005. 